\title{
Energy Efficiency of Rotary Digesters
}

\author{
G. A. GOLUB ${ }^{1}$, K. SZALAY², S. M. KUKHARETS ${ }^{3}$, \\ O. A. MARUS ${ }^{*}$
}

\begin{abstract}
In this paper, a new technical solution is introduced for the substrate mixing in a digester. The novelty content lies in the direction changes of the gravitational forces that influence the movement of organic and mineral biomass fractions. Digester case is designed as a horizontal cylinder rotating around a horizontal axis. Digester rotates in water that is in the outer casing.

This design creates a lift force for rotating digester which reduces the load on the bearings. The friction is reduced and therefore it reduces the energy loss of digester rotation and mixing of the substrate.
\end{abstract}

Keywords: biogas, rotating digester, manure, mixing

\section{Introduction}

One of the elements of non-waste industry of agricultural production is the processing and application of manure. Intensive agricultural production causes the deterioration of the biological properties of the soil and its degradation. Therefore, there is a need for processing manure of cattle and pigs into complete organic fertilizers using technologies of biogas fermentation and composting. The produced biofuel allows to partially replace fossil energy (Pollmann, Podruzsik, Fehér 2014, Golub, Kukharets, Yarosh, Kukharets 2017).

Biogas plants can be used to produce renewable energy and environmentally friendly organic fertilizers. They provide improvement of sanitary-epidemiological state of the environment. A wide range of raw materials can be used for the process (Geletukha, Zheleznaya 2012).

Biogas plants play an important role in today's agriculture. In order to improve the efficiency of their operation the optimization of technological

*Addresses for correspondence: G. A. Golub (gagolub@ukr.net), K. Szalay (szalay.kornel@mgi.naik.hu), S. M. Kukharets (saveliy_76@ukr.net), O. A. Marus (marus_o@ukr.net)

${ }^{1}$ National University of Life and Environmental Sciences of Ukraine, Ukraine

2 National Agricultural Research and Innovation Center Institute of Agricultural Engineering, Hungary

${ }^{3}$ Zhytomyr National Agroecological University, Ukraine 
processes, justification and selection of rational parameters of machines and equipment are required.

Substrate biomass layering greatly reduces the efficiency of the methane generation because of the spatial distribution of methaneproducing microorganisms and organic matter. Effective interaction of anaerobic bacteria with biomass is ensured by substrate mixing. However, too intense mixing can lead to deterioration of anaerobic digestion (Uçkun Kiran, Stamatelatou, Antonopoulou, Lyberatos 2016, Borja, Rincón 2017). The compromise can be achieved by using slow rotation of mixing machines or by their short work period (Geletukha, Kucheruk, Matveev 2013, Goux, Calusinska, Fossépré, Benizri, Delfosse 2016, Satjaritanun, Khunatorn, Vorayos, Shimpalee, Bringley 2016). However, it is impossible to completely eliminate the layering of biomass in a reactor into mineral sediment and organic floating biomass (Geletukha, Kucheruk, Matveev 2013, Satjaritanun, Khunatorn, Vorayos, Shimpalee, Bringley 2016).

A significant amount of fresh water is used to prepare biomass for fermentation. To reduce water consumption, it is important to develop technologies that can provide the expected density of the manure during removal from livestock buildings.

The efficiency of biogas production depends on the characteristics of biomass (density, dry matter content, particle size of dry matter) (Vojtela et al. 2010, 2013) and features of the digester (mixing intensity, geometric dimensions, the way of placement of blades, mixers and walls inside digester) (Adouani, Pons, Hreiz, Pacaud 2016, Carrere, Antonopoulou, Affes, Passos, Battimelli, Lyberatos, Ferrer 2016). The effectiveness depends on the control of digesters (Warda, Hobbs, Holliman, Jones 2008). An embedded rotating digester can be used to avoid the layering of biomass (Golub, Kukharets, Yarosh, Kukharets 2017, Golub, Kukharets 2015). To increase the efficiency of biogas production in rotating reactors the reduction of energy demand of substrate mixing is needed. Furthermore, it is important to be aware of the efficiency of rotating digesters.

The aim is to increase the level of energy efficiency of biogas production by improving the technologies of the substrate preparation and digester design. One possible way is to use improved energy efficiency rotating digesters for biogas production.

\section{Aim of the study}

The aim of the study was to test our hypothesis that the energy loss during the rotating digesters can be reduced if the rotating digester is partly sunk 
into water. In order to verify the hypothesis an experimental digester was used. The primary objectives of the study were to evaluate energy consumption under different operation conditions of a rotating digester and to establish the basic geometrical correlations and kinematics to describe the optimum when manufactured in plant scale. The biogas production was not tested. The plant scale rotating digester manufacturing and testing and the general study of achievable biogas production effectiveness remain for future experiments and studies.

\section{Materials and methods}

The investigation was carried out by using an experimental digester (Fig. 1) (inner radius $\mathrm{R}=0.2 \mathrm{~m}$, working length $\mathrm{L}=0.6 \mathrm{~m}$ ). Cattle and pig manure were used as substrates. The research was done in a small scale laboratory digester.

The digester was supported by slipping bearings. Its internal volume is $78.7 \mathrm{~L}$, the external is $80 \mathrm{~L}$. Temperature regulation was solved with built-in electric heaters with sensors to maintain water temperature at $36-38{ }^{\circ} \mathrm{C}$ (adjustable). Three phases electric motor with a power of $100 \mathrm{~W}$ was used to drive the digester. Digester rotation speed was 10 turn per minute. The power consumption change was measured in the course of $450 \mathrm{~s}$ in case of settings. Measurements were made in five repetitions. The average power consumption value was calculated.

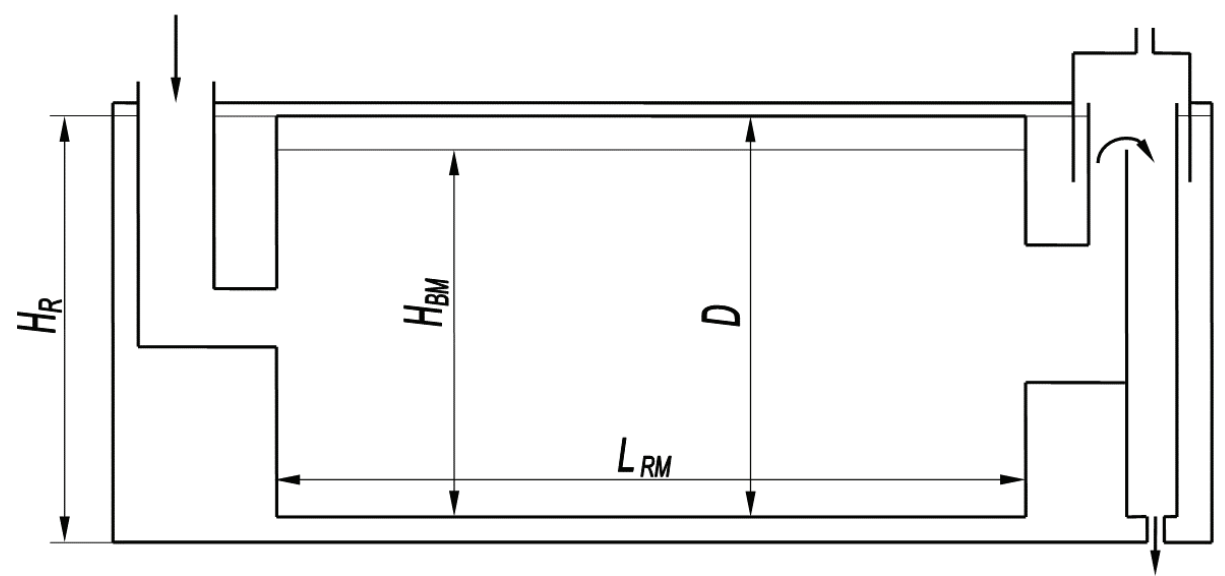

Figure 1. Design model of rotary digester (explained in the text) 
Design model of rotating reactor, which is used in research, is shown in Fig. 2. In order to ensure the rotation of the reactor it is necessary to apply rotational moment the value of which is:

$$
M_{R M}=M_{R A}+M_{V F O}+M_{V F I}+M_{R B}-M_{L B}+J \frac{d \omega}{d t}
$$

where $M_{R M}$ - rotational moment to ensure the rotation, $\mathrm{H} \mathrm{m} ; M_{R A}$ - the moment of resistance of bearing assembly, $\mathrm{H} \mathrm{m} ; M_{V F O}$ - the moment of viscous friction of the digester outer surface against water into which the digester is immersed, $\mathrm{H} \mathrm{m} ; M_{V F I}$ - the moment of viscous friction of digester inner surface against liquid biomass inside digester, $\mathrm{N} \mathrm{m} ; M_{R B}$ - the moment required to ensure the lifting of biomass in the digester during its rotation, $\mathrm{H} \mathrm{m} ; M_{L B}$ - the moment generated by lowering the flows of biomass inside the digester during its rotation, $\mathrm{H} \mathrm{m}$; $J$ - the moment of digester inertia over the axis of its rotation, $\mathrm{kg} \mathrm{m}^{2} ; \frac{d \omega}{d t}$-digester angular rotation acceleration, $\mathrm{rad} / \mathrm{s}^{2}$.
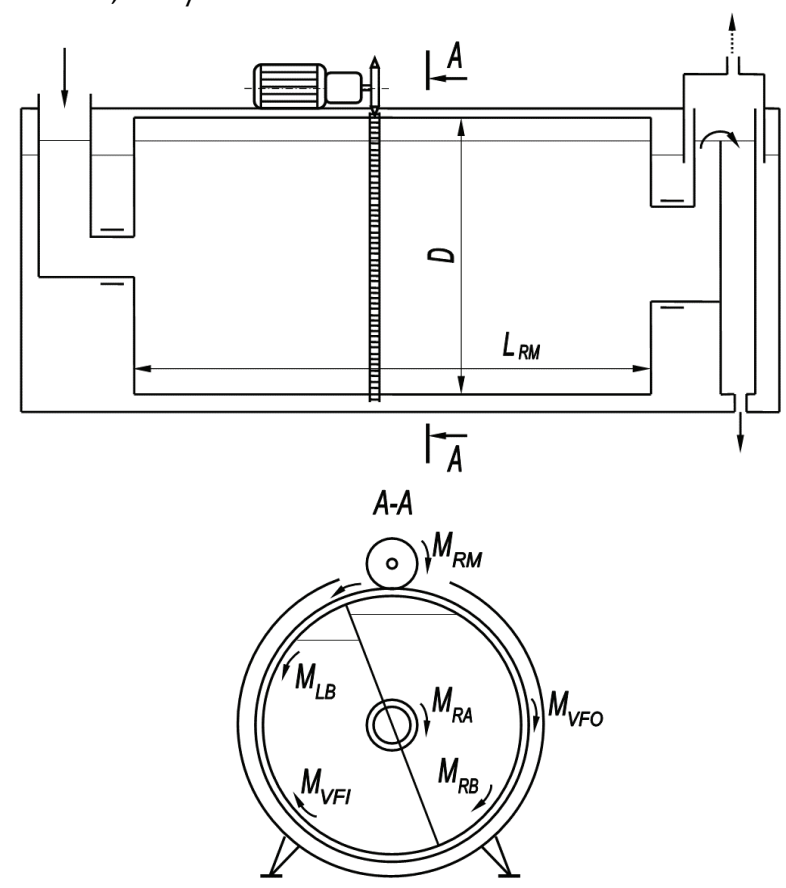

Figure 2. Design model of rotating digester (explained in the text) 
It consisted (Fig. 3) of a rotating digester BOR-0.4 (1), the outer casing, frequency converter Hitachi-3-G3JX-A4075-EF (2), laptop (3) and a digital meter DMK-30 (4).

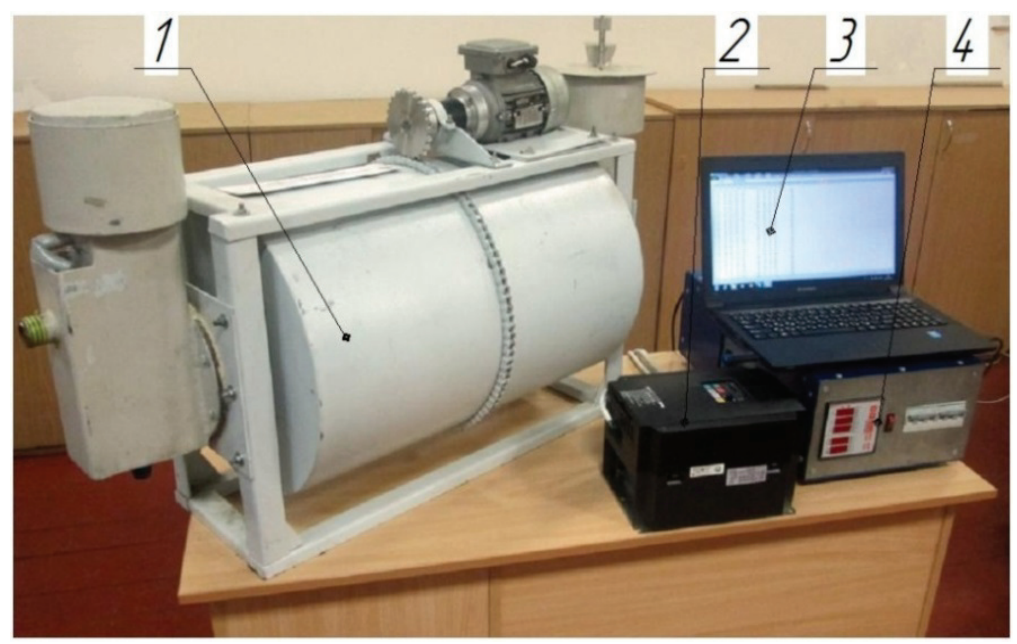

Figure 3. Equipment for studying the efficacy of substrate mixing (the outer casing is not shown)

The optimal biogas production was expected to take place under the following conditions: temperature of $38-55^{\circ} \mathrm{C}$, substrate acidity of $6.5-7 \mathrm{pH}$ values, and substrate moisture content of $90-95 \%$. The maximum size of solid components of the substrate is up to $30 \mathrm{~mm}$. However, biogas production efficiency was not evaluated in this experiment.

\section{Results}

A new technical solution has been developed for substrate mixing in a digester. The idea is based on the changes in the direction of the gravitational forces that influence the movement of organic and mineral fractions of biomass. The digester casing is designed as a horizontal cylinder that rotates around a horizontal axis. Digester rotates in the fluid that is in the outer casing. This design creates a lift force for rotating digester. Meanwhile, the friction is reduced and therefore it reduces the energy loss for digester rotation and mixing of the substrate. The design of digester also 
eliminates the possibility of creating floating organic part and immersed mineral sediment.

To ensure the floating of the digester it is necessary to follow the Archimedes principle:

$$
\rho_{L} V_{I}=\rho_{L} V_{R M} \varepsilon=m_{M}+m_{B M}+m_{B G}
$$

where $\rho_{L}$-the density of the water where the rotating digester is immersed, $\mathrm{kg} / \mathrm{m}^{3} ; V_{I}$ - the volume of the immersed into water rotary digester, $\mathrm{m}^{3} ; V_{R M}$ - the whole volume of rotary digester, $\mathrm{m}^{3} ; \varepsilon=\frac{V_{I}}{V_{R M}}-$ the degree of immersion of rotating digester into water, relative units; $m_{M}$ - the mass of metal of rotating digester, $\mathrm{kg} ; m_{B M}$ - the mass of organic material in a rotating digester, $\mathrm{kg} ; m_{B G}-$ the mass of biogas in rotating digester, $\mathrm{kg}$.

Dividing the components of equation (2) by $\rho_{L} V_{R M}$ the value of immersion of the rotating digester into water is:

$$
\varepsilon=\frac{m_{M}}{\rho_{L} V_{R M}}+\frac{V_{R M} \gamma \rho_{B M}}{\rho_{L} V_{R M}}+\frac{V_{R M}(1-\gamma) \rho_{B G}}{\rho_{L} V_{R M}}=\frac{m_{M}}{\rho_{L} V_{R M}}+\gamma \frac{\rho_{B M}}{\rho_{L}}+(1-\gamma) \frac{\rho_{B G}}{\rho_{L}},
$$

where $\gamma$-coefficient of filling of rotating digester with organic biomass, relative units; $\rho_{B M}$ - density of organic materials in rotating digester, $\mathrm{kg} / \mathrm{m}^{3} ; \rho_{B G}$ - density of biogas in rotating digester, $\mathrm{kg} / \mathrm{m}^{3}$.

The density of the fluid, where the rotary digester is immersed, is approximately equal to the density of the organic material in a rotating digester; biogas density in rotating digester is less than the density of fluid where the rotating digester is immersed, so it can be described:

$$
\varepsilon=\frac{\rho_{M} V_{M}}{\rho_{L} V_{R M}}+\gamma
$$

where $\rho_{M}$ - metal density, $\mathrm{kg} / \mathrm{m}^{3} ; V_{M}$ - the volume of metal used to produce rotary digester, $\mathrm{m}^{3}$.

The level of immersion of the rotating digester into water is defined by the level of filling of rotating digester with organic biomass and the ratio of 
the mass of metal of rotating digester and the fluid that is pushed out when it is immersed.

The ratio of metal mass used in rotary digester and fluid that is displaced when the digester is sunk, given that it has a cylindrical shape can be calculated:

$$
\begin{gathered}
\frac{\rho_{M} V_{M}}{\rho_{L} V_{R M}}=\frac{\rho_{M}\left(2 S_{E}+S_{L}\right) \delta}{\rho_{L} \frac{\pi D^{2}}{4} L_{R M}}=\frac{\rho_{M}\left(2 \frac{\pi D^{2}}{4}+\pi D L_{R M}\right) \delta}{\rho_{L} \frac{\pi D^{2}}{4} L_{R M}}=\frac{4 \rho_{M} \delta\left(\frac{D}{2}+L_{R M}\right)}{\rho_{L} D L_{R M}} \\
=\frac{\rho_{M} \delta}{\rho_{L}} \frac{\left(2 D+4 L_{R M}\right)}{D L_{R M}}=\frac{\rho_{M} \delta}{\rho_{L} D}\left(2 \frac{D}{L_{R M}}+4\right),
\end{gathered}
$$

where $S_{E}$ - the area of the base surface of a rotating cylindrical rotating digester, $\mathrm{m}^{2} ; S_{L}$-the lateral surface of a cylindrical rotating digester, $\mathrm{m}^{2}$; $\delta$-thickness of metal used for producing cylindrical rotating digester, $\mathrm{m}$; $D$ - diameter of cylindrical rotating digester, $\mathrm{m} ; L_{R M}$-the length of the cylindrical rotating digester, $\mathrm{m}$.

Dependence on the determination of the immersion value of rotating digester into water is the following:

$$
\varepsilon=\frac{\rho_{M} \delta}{\rho_{L} D}\left(2 \frac{D}{L_{R M}}+4\right)+\gamma .
$$

Dependence on the level of immersion of rotating digester into water on the length of digester with its diameter of $2.5 \mathrm{~m}$, metal thickness of $5 \mathrm{~mm}$ and coefficient of filling of rotating digester with organic biomass of 0.8 relative units, is shown in Fig. 7. The level of sinking of the rotating digester into water is smaller than one. It is therefore necessary to set the height of the water level into which the rotating digester is sunk:

$$
\varepsilon=\frac{V_{I}}{V_{R M}}=\frac{S_{I} L_{R M}}{S_{E} L_{R M}}=\frac{S_{I}}{S_{E}}=\frac{4 S_{I}}{\pi D^{2}},
$$

where $S_{I}$-immersed area of the base surface of the rotating cylindrical digester, $\mathrm{m}^{2}$.

The level of immersion of the rotating digester into water: 


$$
\varepsilon=1-\frac{1}{\pi} \arccos \frac{2 h}{D}+\frac{4 h}{\pi D^{2}} \sqrt{\frac{D^{2}}{4}-h^{2}} .
$$

Calculation of the distance from the center of a cylindrical rotating digester to the level of water in which it is immersed is made in a way that the value of the level of sunk of the rotating digester into a water is determined by formula (6), and is equal to the value of immersion defined by the expression (8).

When the rotary digester is completely sunk (Fig. 7) into the water the coefficient of filling of the rotating digester with organic biomass is determined by the following formula (9):

$$
\gamma=1-\frac{\rho_{M} \delta}{\rho_{L} D}\left(2 \frac{D}{L_{R M}}+4\right)
$$

Energy properties of the experimental equipment (laboratory scale)

Multiplying each element of the formula (1) to the angular rate of the reactor rotation leads to:

$$
P_{R M}=P_{R A}+P_{V F O}+P_{V F I}+P_{R B}-P_{L B}+J \omega \frac{d \omega}{d t},
$$

where $\omega$ - angular rate of digester rotation, $\mathrm{rad} / \mathrm{s} ; P_{R M}-$ power to provide digester rotation, $\mathrm{W} ; P_{R A}$ - power of bearing assembly resistance, $\mathrm{W} ; P_{V F O}-$ power of viscous friction of digester outer surface over water into which the digester is immersed, $W ; P_{V F I}$ - power of viscousfriction of digester inner surface over the liquid biomass contained in digester, $\mathrm{W} ; P_{R B}$ - power to ensure the lifting of biomass in the digester during its rotation, $W ; P_{L B}$ - power of the flow in biomass lowers in digester during its rotation, W.

Thus, the power which is consumed by the drive motor from the electricity mains will be:

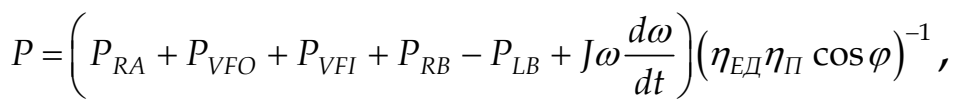

where $P$ - the power consumed by the drive motor from the electricity mains, $\mathrm{W} ; \eta_{E}$ - performance factor of the electromotor, relative unit; $\eta_{D}$ performance factor of the drive, relative unit; $\cos \varphi$ - the proportion of active power at electromotor gross power, relative unit.

Equation (11) is an energy balance of the rotating reactor drive. The constant value of consumed power is possible only at full filling of the 
internal digester volume. As part of digester volume is filled with biogas, internal overflows of water in the digester will lead to cyclical shocks that will break the static equilibrium of a rotating reactor and lead to cyclic load changes.

The actual change of the consumed power which is spent on the drive of an experimental reactor filled by $96 \%$ with an internal volume of $75.55 \mathrm{~L}$ ( $0.4 \mathrm{~m}$ in diameter) and on its level of sinking in water by $75 \%$ is given in Fig. 4.

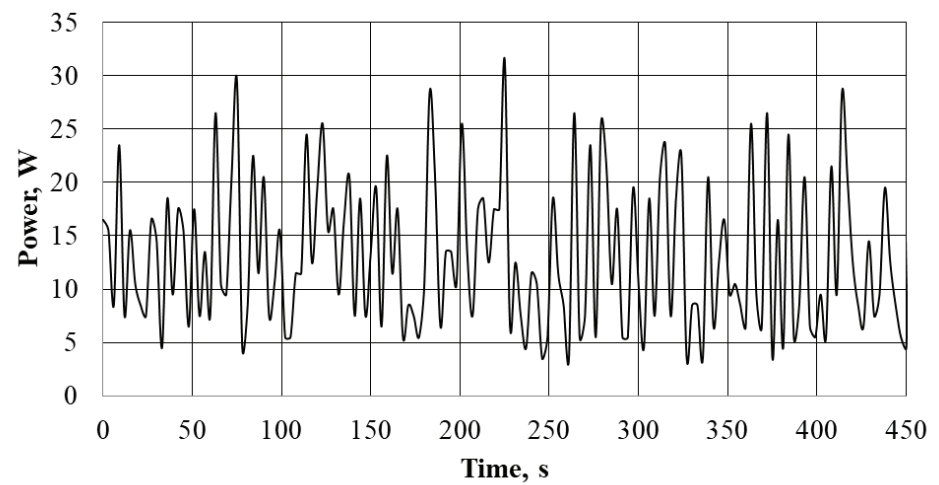

Figure 4. Change of a power consumption during the rotary reactor operation

These results are obtained during the operation of the experimental installation shown in Fig. 3. Based on these data an average value of the power for rotation of digester in water and the specific power of a driving mechanism for the digester rotation was calculated. This data is indicative for the design of a rotating digester for industrial use.

We have measured the average power necessary for the small scale rotary reactor drive depending on its filling coefficient (Fig. 5).

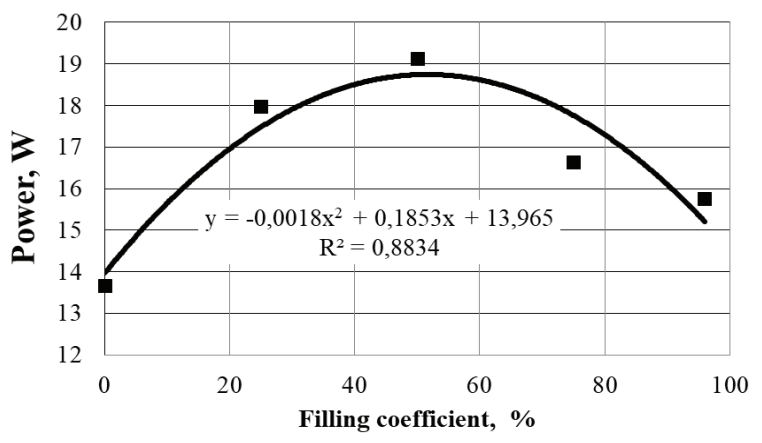


Figure 5. The effect of the rotary reactor filling coefficient on the driving mechanism power uptake

We have experimentally determined the average power necessary for the small scale rotary reactor drive depending on its filling coefficient (Fig. 5).

The average power uptake necessary for the rotary reactor drive depending on its coefficient of dipping is given in Fig. 6.

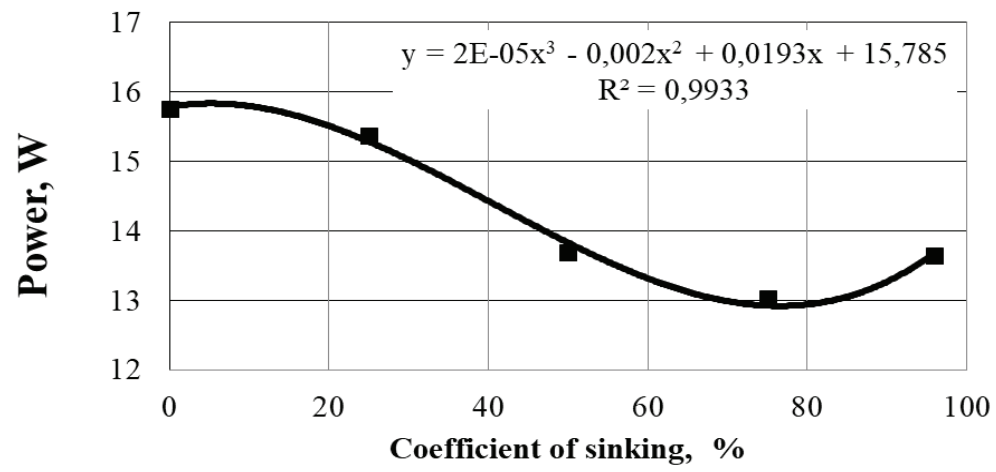

Figure 6. The effect of the coefficient of sinking of a filled rotary digester on the driving mechanism power

In order to get intermediate data between settings above (Figs 5, 6) we fitted a polynomial curve. We accepted the lowest polynomial function which provided with the good results.

After the analysis we can state that the rotary reactor with internal volume of $75.55 \mathrm{~L}(0.4 \mathrm{~m}$ in diameter $)$ filled by $96 \%$ requires minimum power of $13 \mathrm{~W}$ for drive when dipping it into water by 75-77\%. Herewith, the specific power of a driving mechanism with a view to biomass volume in a reactor will be $0.179 \mathrm{~kW} / \mathrm{m}^{3}$.

\section{Plant scale calculation}

By describing the basic geometrical correlations we could calculate the operation conditions of a plant scale rotating digester within length range of 4-10 m. However, the power requirements of rotating a plant scale rotating digester were not determined.

Coefficient of filling of a plant scale rotating digester with organic biomass is determined by its geometrical dimensions (Fig. 7). 
This dependence is received according to formula (6). The graph shows the dependence between the value of the level of sinking into water and the length of the digester. This kind of dependence is conditioned by the fact that the increase of digester's length will result in additional metal. The weight, however, will not increase linearly to the increase of total surface to which the buoyancy force acts. This leads to an improved digester floating a reduced level of sinking.

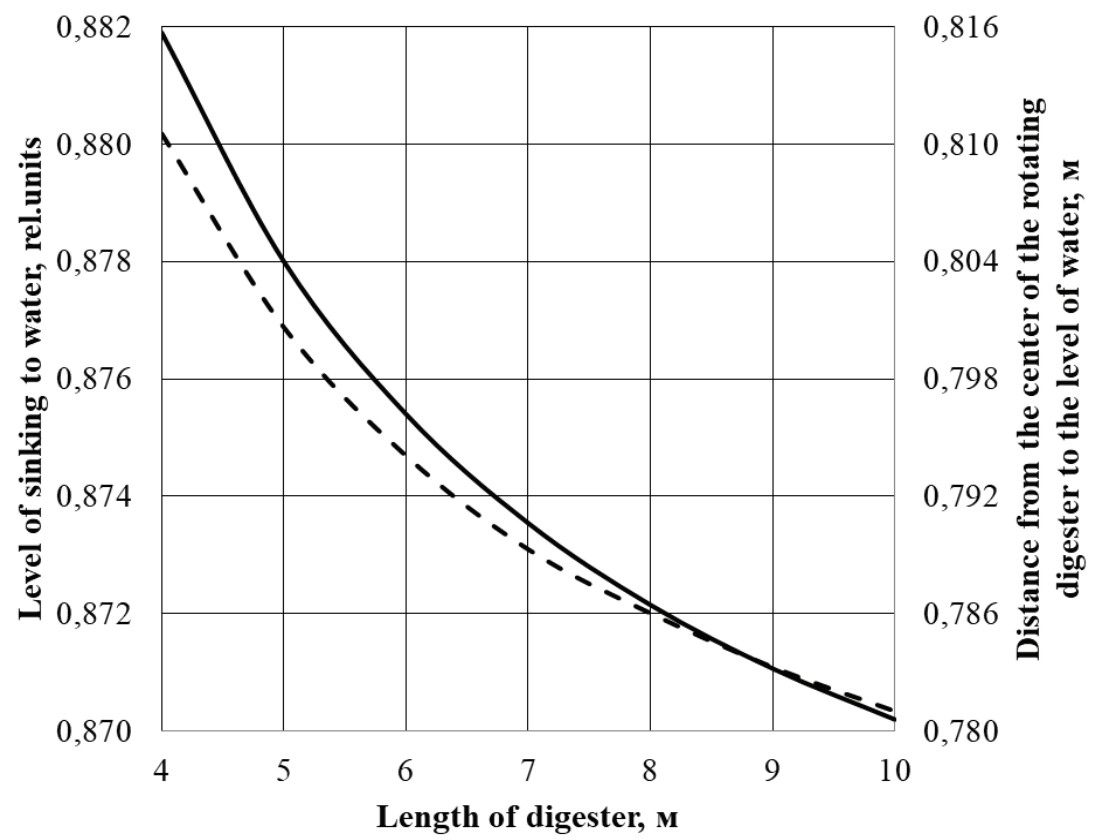

Figure 7. Dependence of the level of sinking into water (main line on the main scale) and the distance from the center of the rotating digester to the level of water into which it is sunk (bar dotted line in auxiliary scale) on the length of a plant scale digester

Calculation of the distance from the center of the rotating digester to the level of organic biomass was made in case of plant scale (Fig. 8). The coefficient of filling of rotary digester with organic biomass is determined by formula (9). It is equal to the coefficient of filling the rotating digester with organic biomass determined by the expression (8) when substituted $\varepsilon=\gamma$.

This dependence is received according to formula (9). The graph shows the dependence between the coefficient of filling and the length of the 
digester. In this kind of dependence the fact that as the length of digester increases the buoyancy force acting to the digester increases accordingly also comes into play so the filling coefficient will increase as well.

The coefficient of filling does not change if the digester is rotating or not. Rotation slightly changes the axis of symmetry. As a result of rotating the average sinking level of digester does not change (water level on the rotation direction increases, on the opposite side decreases).

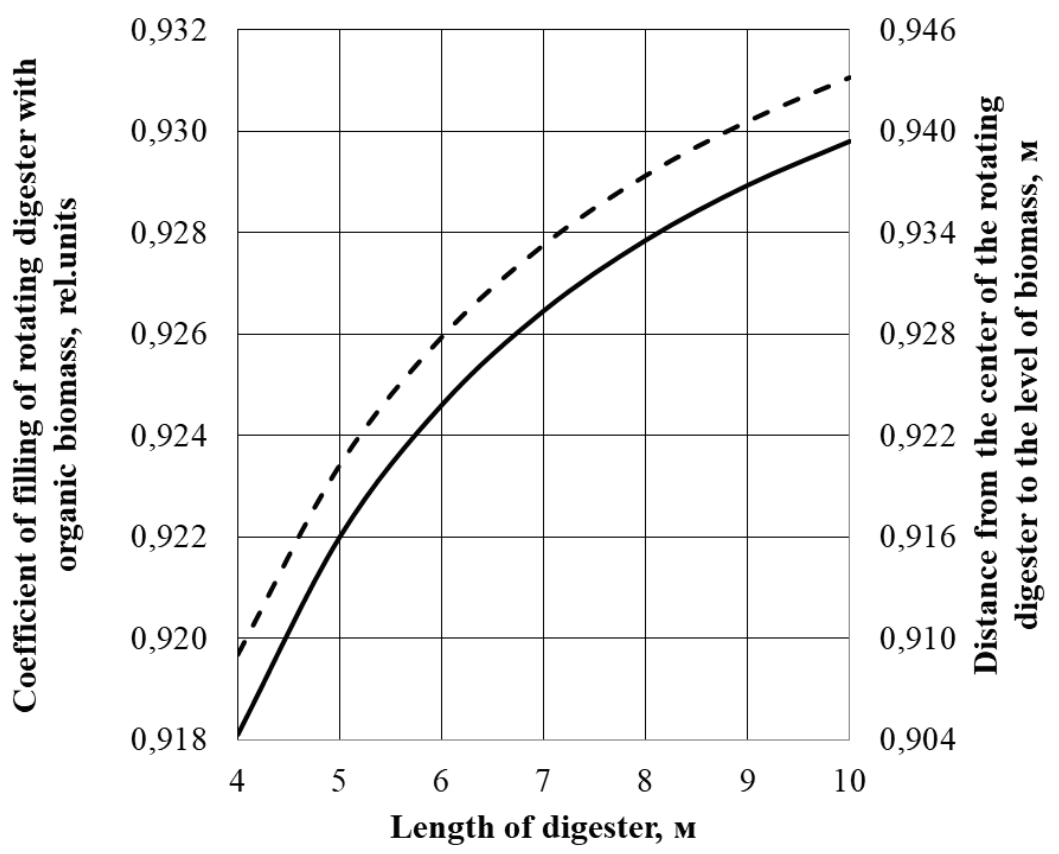

Figure 8. Dependence of the coefficient of filling of a rotating digester with organic biomass (main line on the main scale) and distance from the center of the rotating digester to the level of biomass in a rotating digester (bar dotted line in auxiliary scale) on the length of plant scale digester

\section{Discussion}

When the coefficient of sinking of a rotary reactor increases, the average magnitude of a power uptake increases as well. It is explained by the increased resistance and energy loss in the bearing system. There is also some stringy friction between a reactor internal surface and liquid biomass which is in a reactor. The power is also consumed to provide biomass lifting 
in a reactor during its rotation. In case of the further filling of the rotary reactor the average magnitude of power consumption somewhat decreases due to the decrease in biomass flow inside a reactor.

In case the sinking coefficient of rotary reactor increases up to the range of $70-85 \%$ the average magnitude of power consumption decreases to its minimum. It is explained by a decrease in energy loss due to the resistance in a bearing system. The average magnitude of the power consumption somewhat increases as a function of friction between the external surface of a reactor and the water into which the reactor has been sunk.

Keeping the rotary digester sunk in water provides minimal energy consumption for its rotation. Reduced water use and increased efficiency of compost production can be achieved by professional collecting and handling of animal manure from livestock farms. The conducted research does not provide the conclusions about the influence of the reactor on the efficiency of biogas production but shows an interesting technical solution to reduce the energy loss of mixing process in small, laboratory case. In order to evaluate the behavior of the model in standard plant scale (at a biogas plant level) further models are required. The continuation of the study promises valuable results to increase the energy efficiency of manure utilization and biogas production.

\section{Conclusions}

In case of livestock farms manure management, which includes the collecting, handling and further use, the careful organization is a very important issue. Spent manure and litter can be used as a compost raw material. The resulting compost material as soil conditioner can be spread to arable land.

The obtained formulas allow determining the optimal level of sinking of the rotating digester (70-85\%), its filling factor depending on digester geometrical parameters and density of water or other fluid with which the digester's external housing is filled in to increase the energy efficiency of rotating operation.

The rotary digester with an internal volume of $75.55 \mathrm{~L}(0.4 \mathrm{~m}$ in diameter) filled by $96 \%$ requires $13 \mathrm{~W}$ power to be rotated when sunk into water by $75-77 \%$. The specific power requirement used for rotating per biomass volume based on the experimental results is calculated to be 0.179 $\mathrm{kW} / \mathrm{m}^{3}$ 
Based on the established and described correlations the small scale model was extended to plant size rotating digesters and the size optimum was calculated. The optimal size was determined by the asymptotic nature of the formula describing the length and based on economical aspects of manufacturing, operating. The research will continue by manufacturing and testing the operational conditions and energy efficiency of rotating digesters sunk in water with length range of 8-10 m.

\section{References}

Adouani, N., Pons, M.-N., Hreiz R., Pacaud, S. (2016) Dynamic modelling of an anaerobic digester for wastes at the territory level. In IFAC-PapersOnLine 49(7): 1169-1174, https://doi.org/10.1016/j.ifacol.2016.07.361.

Biogas Production: Borja, R., Rincón, B. (2017) In Reference Module in Life Sciences, Elsevier, Current as of 28 February 2017, 24, https://doi.org/10.1016/B978-0-12809633-8.09105-6.

Carrere, H., Antonopoulou, G., Affes, R., Passos, F., Battimelli, A., Lyberatos, G., Ferrer, I. (2016) Review of feedstock pretreatment strategies for improved anaerobic digestion: From lab-scale research to full-scale application. In Bioresource Technology 199: 386-397, https:/ / doi.org/10.1016/j.biortech.2015.09.007.

Geletukha, G., Kucheruk, P., Matveev, Y. (2013) Development of biogas technology in Ukraine and Germany: normative - legal framework and prospects: Kyiv Hyultsov, 75.

Geletukha, G.G., Zheleznaya, T.A., (2012) The place of bioenergy in development updated energy strategy of Ukraine until 2030: Bioenergy Association of Ukraine, 11.

Golub, G.A., Kukharets S.M. (2015) Methane tank. Patent of Ukraine for invention No. $110077,6$.

Golub, G.A., Kukharets, S.M., Yarosh, Y.D., Kukharets, V.V. (2017) Integrated use of bioenergy conversion technologies in agroecosystems. INMATEH - Agricultural Engineering 51 (1): 93-100.

Goux, X., Calusinska, M., Fossépré, M., Benizri, E., Delfosse, P. (2016) Start-up phase of an anaerobic full-scale farm reactor - Appearance of mesophilic anaerobic conditions and establishment of the methanogenic microbial community. In Bioresource Technology 212: 217-226, https://doi.org/ 10.1016/j.biortech. 2016.04.040.

Pollmann, O., Podruzsik, S., Fehér, O. (2014) Social acceptance of renewable energy: some examples from Europeand developing Africa. Society and Economy 36 (2): 217-231.

Satjaritanun, P., Khunatorn, Y., Vorayos, N., Shimpalee S., Bringley, E. (2016) Numerical analysis of the mixing characteristic for napier grass in the continuous stirring tank reactor for biogas production. Biomass and Bioenergy 86: 53-64, https://doi.org/10.1016/j.biombioe.2016.01.018. 
Uçkun Kiran, E., Stamatelatou, K., Antonopoulou, G., Lyberatos, G. (2016) Production of biogas via anaerobic digestion. In Handbook of Biofuels Production (Second Edition). Woodhead Publishing: 259-301, https://doi.org/10.1016/B978-0-08100455-5.00010-2.

Vojtela, T., Pazsiczki, I., Kelemen, Zs., Bak, J., Kocsis, L., Fenyvesi, L. (2010) Harvesting silage maize for needs of dairy cows and/or needs of biogas facilities. 3rd IFSDAA International Seminar on Crop Science for food security, bio-energy and sustainability conference Book of Abstracts, 2010 Szeged, Hungary

Vojtela, T., Tóvári, P., Fenyvesi, L. (2013) Utilization opportunities of biomass mixtures by thermochemical conversion and anaerobic fermentation in Hungary, Bioenergyevent 2013, Jyväskylä, Finland, 4-6 September 2013

Warda, A.J., Hobbs, P.J., Holliman, P.J., Jones, D.L. (2008) Optimisation of the anaerobic digestion of agricultural resources. Bioresource Technology 99(17): 7928-7940, https:// doi.org/10.1016/j.biortech.2008.02.044. 